\title{
Radiation Exposure due to CT of the Scaphoid in Daily Practice
}

Andele D. de Zwart ${ }^{1 *}$, Frank J.P. Beeres ${ }^{2}$, Mike Pillay ${ }^{3}$, Lucas M. Kingma ${ }^{3}$, Inger B. Schipper ${ }^{4}$ and Steven J. Rhemrev ${ }^{5}$

${ }^{1}$ Department of Orthopedics, University Medical Centre Groningen, 9700 RB, Groningen, Netherlands

${ }^{2}$ Department of Surgery, Luzerner Kantonsspital, 6006, Luzern, Zwitserland

${ }^{3}$ Department of Radiology, Medical Centre Haaglanden, 2512 VA, The Hague, Netherlands

${ }^{4}$ Department of surgery, Leiden University Medical centre, Postbus 9600, 2300 RC, Leiden, Netherlands

${ }^{5}$ Department of Surgery, Medical Centre Haaglanden, 2512 VA, The Hague, Netherlands

"Corresponding author: Andele D. de Zwart, Department of Orthopedics, University Medical Centre Groningen, 9700 RB, Groningen, Netherlands, Tel: 0031624253901; E-mail: p.krijnen@lumc.nl

Received date: May 19 2015, Accepted date: June 08; 2015, Publication date: June 12; 2015

Copyright: ( $) 2015$ de Zwart AD, et al. This is an open-access article distributed under the terms of the Creative Commons Attribution License; which permits unrestricted use; distribution; and reproduction in any medium; provided the original author and source are credited.

\section{Abstract}

Study background: The aim of this study was to measure radiation exposure including scatter radiation, resulting from CT of the scaphoid in different settings as used in daily practice and to calculate the effective dose (ED) using a wrist phantom.

Methods: The radiation exposure was quantified for five different CT protocols, all used in daily practice for the scaphoid CT. Two protocols concerned a CT of the scaphoid with a plaster cast of the hand and three protocols without. For all protocols the Computed Tomographic Dose Index weighted (CTDIw), the scatter dose to the brain and scatter dose to the torso were derived from the CT and measured externally with the Piranha dose meter.

Results: The average CTDIw was $2.18 \mathrm{mGy}$. The average scatter to the brain and torso was $0.011 \mathrm{mSv}$. The average estimated ED was $0.02 \mathrm{mSv}$ (range 0.02 to 0.04 ) of which $0.0008 \mathrm{mSv}$ (range 0.0003 to 0.0012 ) was due to the scatter radiation. The two CT protocols of the scaphoid performed with a plaster cast resulted in a $90 \%$ higher ED, although the power of the study was too low to demonstrate this statistically.

Conclusion: The CT protocols used for scaphoid analyses in a plaster cast immobilized hand may result in higher radiation exposure than without plaster cast. We therefore recommend, whenever possible, performing CT of the hand and wrist without a plaster cast.

Keywords: Computed tomography; Diagnostic imaging; Dose; Scattered; Effective dose

\section{Introduction}

Computer Tomography (CT) is often used in the diagnostic workup of clinically suspected scaphoid fractures that are not evident on plain radiographs. CT is readily available, cheap, and fast [1]. The assumed specificity is $99 \%$ and sensitivity $93 \%$ [2], although a recent study showed a lower sensitivity of around $70 \%$ [3]. Despite its moderate sensitivity, CT remains the investigation of choice for the triage of suspected scaphoid fractures in many hospitals. A disadvantage of CT is the exposure to radiation. Since the damaging impact of radiation on tissue in the body is cumulative, radiation exposure should be kept as low as possible throughout a patient's life according to the philosophy of ALARA (As Low as Reasonably Achievable) [4]. Moreover investigations have shown an increased risk of cancer after exposure to low dose radiation [5]. Radiology departments in Europe are obliged to abide by set reference levels of radiation exposure for each procedure according ICRP (International Commission for Radiation Protection) and the European EURATOM guidelines [6]. Diagnostic reference levels (DRL) for the extremities are currently being developed and, therefore, not yet available for CT of the scaphoid. Moreover, the DRL measurements do not include scatter radiation.

This study was designed to determine the radiation exposure of a CT of the scaphoid, including the scatter radiation, mimicking different clinical settings (with and without a plaster cast) in a phantom. These findings are of interest for clinicians and patients who should be informed of the potential health hazards they are subjected to.

\section{Materials and Methods}

This study does not involve humans or animals. Therefor approvement by the regional Medical Ethics Committee was not needed.

\section{Radiation measurements}

The direct radiation exposure on PMMA (polymethylmetgacrylate) wrist phantoms was measured. The construction of the phantom was based on the phantom description by Robertson et al. The phantom was constructed accordingly in our radiotherapy moldroom (Figure 1) [7]. The radiation dose was measured in CTDIw using the Piranha dose meter with a SD16 ionising chamber. For the scatter measurements the Victoreen 451B ionizing chamber was used. 
Page 2 of 4

The measurements were taken in two different settings. The CTDI measuring chamber was placed inside the wrist phantom for measurement of the radiation exposure due to the primary beam and the Victoreen $20 \mathrm{~cm}$ above the wrist phantom (where the head would be in a clinical situation) for measurement of the scatter to the head (Setting A). The CTDI measuring chamber was placed inside the wrist phantom for measurement of the radiation exposure due to the primary beam and the Victoreen dosemeter above the head phantom for measurement of the scatter to the rest of the body (setting B) (Figure 1).
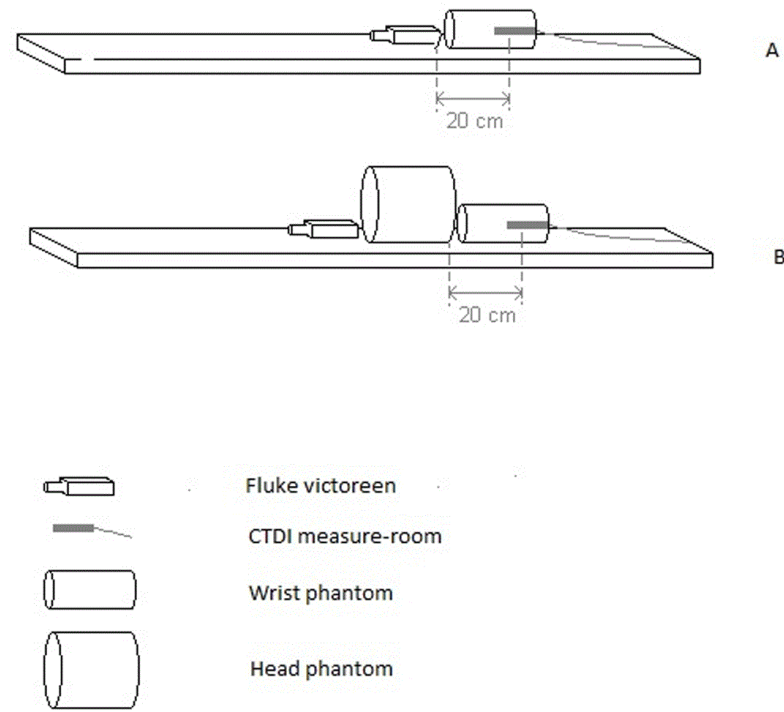

Figure 1: Study design with phantoms for measurements of radiation in two different settings. Setting A: The CTDI measuring chamber was placed inside the wrist phantom for measurement of the radiation exposure due to the primary beam and the Victoreen $20 \mathrm{~cm}$ above the wrist phantom (where the head would be in a clinical situation) for measurement of the scatter to the head. Setting B: The CTDI measuring chamber was placed inside the wrist phantom for measurement of the radiation exposure due to the primary beam and the Victoreen dosemeter above the head phantom for measurement of the scatter to the rest of the body.

The Dose-Length Product (DLP), CT dose index (CTDi) and CT dose index volume (CTDivol) were taken from the CT scanner.

\section{CT protocols}

The radiation exposure was measured with the help of a phantom during five different CT protocols. These 5 protocols are commonly used for in-hospital imaging of the scaphoid. The parameters were chosen on the basis of best images for viewing the scaphoid, produced in the two radiological departments of our clinics. Three protocols concerned a CT of the scaphoid without a plaster cast and two described imaging of the scaphoid in a plaster cast. An overview of CT parameters for the five protocols is given in Table 1. For protocol one, four and five, three measurements were performed in setting $A$ and three measurements in setting B. For protocol two and three, five measurements were performed in setting $\mathrm{A}$ and five in setting $\mathrm{B}$ (Figure 1). Conform our standard acute plaster protocol, a six layer plaster cast was used on the wrist phantom, in the way that it is normally applied in the acute setting. The CT was performed after the plaster had dried completely.

\begin{tabular}{|l|l|l|l|l|l|}
\hline & \multicolumn{3}{|l|}{ Without plaster cast } & \multicolumn{2}{l|}{ With plaster cast } \\
\hline CT 64 slice & Protocol 1 & Protocol 2 & Protocol 3 & Protocol 4 & Protocol 5 \\
\hline $\mathrm{kV}$ & 80 & 80 & 80 & 100 & 100 \\
\hline $\mathrm{mA}$ & 40 & $40-150$ & $40-150$ & 80 & 45 \\
\hline time [s] & 4.6 & 7.8 & 9 & 4.6 & 4.6 \\
\hline Collimation & $32 \times 0.625$ & $32 \times 0.625$ & $32 \times 0.625$ & $32 \times 0.625$ & $32 \times 0.625$ \\
\hline length [mm] & 100 & 185.5 & 185.5 & 100 & 100 \\
\hline rot. time [s] & 0.4 & 0.4 & 0.4 & 0.4 & 0.4 \\
\hline pitch & 0.531 & 0.531 & 0.531 & 0.531 & 0.531 \\
\hline
\end{tabular}

Table1: CT parameters of five different CT protocols for diagnosing occult scaphoid fractures without and with a plaster cast.

The CT images were obtained with a multidetector scanner (General Electric Lightspeed Qx/I CT Scanner, Pewaukee, WI, USA), using the technique described by Sanders [8]. The phantom was positioned as if the patient lay prone on the scanner couch with the hand extended over the patient's head. Section collimation was 0.625 $\mathrm{mm}$ with reconstructions every $0.4 \mathrm{~mm}(120 \mathrm{kVp}, 80 \mathrm{~mA}$, noise index 34). For multiplanar reformatted images, parameters were $2 \mathrm{~mm}$ slice thickness, $2 \mathrm{~mm}$ interval. All scans were obtained in the axial plane. With our 64-slice scanner the voxels are isotropic (i.e. $0.625 \mathrm{~mm}$ in the $\mathrm{X}$-, Y- and Z-plane), so there is no difference with direct oblique coronal scanning. All reconstructions were performed using filtered back-projection. For comparison, no automated dose-reduction schemes were implemented.

\section{With measurements of the CTDIw and the scatter radiation the effective dose (ED) was calculated using the following formula [9]:}

$\mathrm{ED}=(\mathrm{CTDIw} \times \mathrm{WFb} \& \mathrm{~s})+($ ("scatter to the brain" $\times \mathrm{WFb})+($ "scatter to the torso" $\times$ WFt")

Where WFb\&s is the weighting factor for bone and skin (0.01), $\mathrm{WFb}$ is the weighting factor for the brain (0.01), and WFt is the weighting factor for the torso (0.24). The ICRP 103 weighting factors were used [4]. For WFt we summed the weighting factors for lung (0.12), Liver (0.04), Esophagus (0.04) and Thyroid (0.04). Average ED was compared between the protocols with and without plaster cast by means of an unpaired t-test using SPSS version 20.

\section{Results}

Table 2 presents an overview of the mean results for the five different CT protocols. The average ED for all protocols was $0.02 \mathrm{mSv}$. The average ED for CT protocols without a plaster cast was $0.017 \mathrm{mS}$ (standard deviation [SD] 0.001) whereas the average ED for CT protocols with a plaster cast was $90 \%$ higher $(0.032 \mathrm{mSv}$, SD 0.012). The difference in ED between the protocols with and without plaster cast was not statistically significant ( $\mathrm{p}=0.33$ ). The ED due to the scatter radiation ranged from 0.0003 to $0.0012 \mathrm{mSv}$, with an average of 0.0008 mSv. 

CT.

Table 3 gives an overview of the measurements derived from the

\begin{tabular}{|c|c|c|c|c|c|c|}
\hline Protocol & CTDIw (SD) & $\begin{array}{l}\text { Effective Dose } \\
\text { CTDIw }\end{array}$ & $\begin{array}{l}\text { Scatter to the } \\
\text { brain (SD) }\end{array}$ & $\begin{array}{l}\text { Scatter to the } \\
\text { torso (SD) }\end{array}$ & $\begin{array}{l}\text { Efffective Dose } \\
\text { due to scatter }\end{array}$ & $\begin{array}{l}\text { Effective Dose } \\
\text { incl scatter }\end{array}$ \\
\hline & mGy & $\mathrm{mSv}$ & $\mathrm{mSv}$ & $\mathrm{mSv}$ & $\mathrm{mSv}$ & $\mathrm{mSv}$ \\
\hline $1^{*}$ & $1.5(0.01)$ & 0.015 & $0.0045(0.00004)$ & $0.0012(0.00001)$ & 0.0003 & 0.015 \\
\hline 2\# & $1.7(0.01)$ & 0.017 & $0.0094(0.00012)$ & $0.0031(0.00002)$ & 0.0008 & 0.018 \\
\hline $3 \#$ & $1.6(0.01)$ & 0.016 & $0.0080(0.00017)$ & $0.0022(0.00002)$ & 0.0006 & 0.017 \\
\hline average & 1.6 & 0.016 & 0.0073 & 0.0022 & 0.0006 & 0.017 \\
\hline $4 \#$ & $3.9(0.04)$ & 0.039 & $0.010(0.00006)$ & $0.0044(0.00005)$ & 0.0012 & 0.040 \\
\hline $5 \#$ & $2.2(0.01)$ & 0.022 & $0.0076(0.00009)$ & $0.0028(0.00004)$ & 0.0007 & 0.023 \\
\hline Average & 3.1 & 0.031 & 0.0090 & 0.0036 & 0.0010 & 0.032 \\
\hline
\end{tabular}

Table 2: Overview of mean (standard deviation (SD)) for measured CTDIw, scatter to the torso, scatter to the brain and calculated ED for five different CT protocols used for diagnosing occult scaphoid fractures without (1,2 and 3) and with (4 and 5) a plaster cast.

\begin{tabular}{|l|l|l|l|}
\hline Protocol (number of measurements) & DLP & CTDi & CTDivol \\
\hline Without plaster cast & mGycm & & mGy \\
\hline $1(6)$ & $27.7(0.16)$ & $1.4(0.01)$ & $2.8(0.02)$ \\
\hline $2(10)$ & $59.4(0.35)$ & $1.7(0.01)$ & $3.2(0.02)$ \\
\hline $3(10)$ & $54.4(0.27)$ & $1.6(0.01)$ & $2.9(0.01)$ \\
\hline Average & 47.2 & 1.6 & 3.0 \\
\hline With plaster cast & & & $3.8(0.04)$ \\
\hline $4(6)$ & $73.7(0.68)$ & $2.2(0.01)$ & $7.4(0.07)$ \\
\hline $5(6)$ & $70.5(0.40)$ & 3.0 & $4.2(0.02)$ \\
\hline Average & 72.1 & 5.8 \\
\hline
\end{tabular}

Table 3: Mean (SD) for CT measurements recorded by the CT dosismeter for five different CT protocols.

\section{Discussion}

This study provides a quantification of the direct radiation exposure to the wrist when performing a CT of the scaphoid. Moreover, the ED including the scatter radiation to the brain and torso of the patient was quantified. The average ED for all five different CT protocols was 0.02 $\mathrm{mSv}$ which is equivalent to approximately 70 hours of background radiation, when assuming a background radiation of around $2.5 \mathrm{mSV}$ a year [10]. Also, this study showed that the ED is almost twice as high when performing a CT of the scaphoid in a plaster cast compared to the situation without a cast. Due to the limited power of the study, however, this difference could not be demonstrated statistically.

To our knowlegde, one other study investigated the radiation exposure of musculoskeletal CT's and found a radiation exposure of around $0.03 \mathrm{mSv}$, which is little higher than we found [11]. This might be due to the use of modern scanners with better radiation exposure reduction capabilities. It is difficult, however, to compare our study with this study, as they do not describe the CT protocol they use and in what setting there measurements were done. Moreover these results were mathematically estimated from calculations and may not be reliable, and do not account for scatter radiation. Our study used a direct measurement of the radiation exposure and therefore provides more accurate and reliable results.

The radiation exposure of a CT of the wrist is relative low and is comparable with a radiograph of the chest $(0.04 \mathrm{mSv})$ [12]. The effective dose of other common diagnostic imaging procedures ranges from $0.001 \mathrm{mSv}$ for radiography (X-ray)-Extremity, $0.4 \mathrm{mSv}$ for mammography, and $1.5 \mathrm{mSv}$ for radiography (X-ray)-Spine, to $15 \mathrm{mSv}$ 
Page 4 of 4

for Computed Tomography (CT)-Abdomen and Pelvis [13]. However, controversy exists about the dangers of low-dose radiation exposure in the clinical setting. A radiograph of the chest of a female child between the age of 0 and 9 leads to a lifetime risk of cancer of $1.9 \times 10^{-6}$, and a radiograph of the chest between the age of 60 and 69 to a lifetime risk of $0.8 \times 10^{-6}$ [14]. In the LSS Report 13 on the follow-up the 86,000 survivors of Hiroshima and Nagasaki from 1950-1997, it was concluded that solid cancer rates increased linearly with direct evidence of increased cancer incidence from exposures of 0.5 to $2.0 \mathrm{~Sv}$ (500-2,000 $\mathrm{mSv})$, a dose markedly above that of average medical radiation and far more than a CT of the wrist. Further extrapolations of the LSS epidemiological data from low-dose radiation risk of the $65 \%$ of survivors exposed to radiation doses $<100 \mathrm{mSv}$, however, did reveal a statistically significant risk of developing solid tumors even at doses $<100 \mathrm{mSv}$ in a linear non-threshold model [5]. Cancer risks are estimates from epidemiological studies and are subject to active, ongoing debate. Nonetheless, even in the face of disagreement and uncertainty, patient safety requires the assumption that the risk of radiation exposure is real; and that one should strive to maintain the lowest possible lifetime exposures. According to the ALARA philosophy, the radiation exposure must be kept as low as possible. Therefore, when performing a CT of the scaphoid, the CT protocol with the least radiation exposure should be chosen and that would be the protocol without a plaster cast. Also, the radiologist should consider reducing the scatter radiation by means of radioprotective shields whenever possible.

A limitation of the study was that we only measured the radiation exposure acquired by CT system (General Electric) with 5 protocols used in our clinic according the technique of Sanders [8]. Both protocol and CT system may differ per hospital. Additionally, in modern CT scanners it is possible to hold the arm more extended with consequently a greater distance between the wrist and the brain, resulting in lower radiation exposure of the brain.

Secondly, we measured the radiation exposure for only three anatomical areas of the body (i.e., scatter to the brain, scatter to the torso and radiation exposure of the primary beam). We do however feel that the clinically relevant scatter is limited to the brain and torso, and assumed that the scatter to the rest of the body is negligible as scatter is inversely proportional with the distance.

A third limitation is that we have measured three protocols six times and two protocols ten times. There was no statistical base for the number of measurements and there was no specific reason for measuring in different numbers. In interpretation of the result the potential under-powering of this study should be taken into account. However, the range of the results were very small. So we believe these result are valid and reproducable.

Plastic casts could alter radiation exposure as compared to plaster of Paris. We exclusively measured radiation exposure using a dried plaster cast, which is standard in our clinic in the acute setting of wrist and capal fractures and for the first 10 days. At the first outpatient review, the casts will be changed for a plastic cast. In some clinics, CT might be made at this time point, with a plastic cast. The material of the cast may alter the radiation exposure results. In addition, other CT systems and local protocols obviously also could influence the radiation exposures and the use of a phantom as presented in this study could be very useful to analyze the influence of different clinical settings.

Since the wrist is a relatively small object, it in itself does not generate significant scattered radiation. However, the use of different scanning protocols, additional materials (such as casts) could influence the amount of scatter substantially. The scatter components of the CT table are considered a common factor for all CT studies and have therefore been left out of the equation. An evaluation of the table composition and scatter could be a topic of further investigation. In summary, this study provides insight into the radiation exposure for patients with a CT of the wrist or hand, including the scatter radiation. The CT protocols used for scaphoid analysis immobilised in a plaster cast seem to result in higher radiation exposure and measurable scatter. With respect to the ALARA philosophy, CT's of the wrist should preferably be performed without a plaster cast. A radio protective shield for the patient leads to less radiation exposure of the torso and could therefore be considered.

\section{References}

1. Adey L, Souer JS, Lozano-Calderon S, Palmer W, Lee SG, et al. (2007) Computed tomography of suspected scaphoid fractures. J Hand Surg Am 32: 61-66.

2. Yin ZG, Zhang JB, Kan SL, Wang XG (2010) Diagnosing suspected scaphoid fractures: a systematic review and meta-analysis. Clin Orthop Relat Res 468: 723-734.

3. Rhemrev SJ, de Zwart AD, Kingma LM, Meylaerts SA, Arndt JW, et al. (2010) Early computed tomography compared with bone scintigraphy in suspected scaphoid fractures. Clin Nucl Med 35: 931-934.

4. [No authors listed] (2007) The 2007 Recommendations of the International Commission on Radiological Protection. ICRP publication 103. Ann ICRP 37: 1-332.

5. Cardis E, Gilbert ES, Carpenter L, Howe G, Kato I, et al. (1995) Effects of low doses and low dose rates of external ionizing radiation: cancer mortality among nuclear industry workers in three countries. Radiat Res 142: 117-132.

6. ICRP (1996) Recommendations of the International Commission on Radiological Protection. Euratom Directive. ICRP Publication 60. Ann. ICRP 21: 1-3.

7. Roberson PL, Eichner FN, Reece WD (1989) Determination of photon conversion factors relating exposure and dose for several extremity phantom designs. Health Phys 57: 733-741.

8. Sanders WE (1988) Evaluation of the humpback scaphoid by computed tomography in the longitudinal axial plane of the scaphoid. See comment in PubMed Commons below J Hand Surg Am 13: 182-187.

9. http://www.msct.eu/PDF_FILES/Appendix\%20MSCT \%20Dosimetry.pdf.

10. http://www.iaea.org/Publications/Factsheets/English/radlife.html.

11. Biswas D, Bible JE, Bohan M, Simpson AK, Whang PG, et al. (2009) Radiation exposure from musculoskeletal computerized tomographic scans. J Bone Joint Surg Am 91: 1882-1889.

12. https://hps.org/documents/meddiagimaging.pdf.

13. http://www.patient-advocate.com/wordpress/radiation-exposure-in-xray-and-ct-examinations.

14. Wall BF (2004) Radiation protection dosimetry for diagnostic radiology patients. Radiat Prot Dosimetry 109: 409-419. 